\title{
Factors Associated With Misperception of Own Weight Status among 18-21 Year Old University Students
}

\author{
Shagar P.S ${ }^{1}$, Shakiba N ${ }^{2}$, RahmahM.A ${ }^{3}$ \\ ,2,31 (Department of Community Medicine, UKM Medical Centre, Malaysia)
}

\begin{abstract}
This study aimed to determine factors that influence misperception of own weight status among university students aged 18-21years old. A cross sectional study was conducted and 313 respondents aged 18 to 21 years old participated in this study. The questionnaire included questions on socio-demographic factors, eating habits, knowledge on nutrition and obesity, influence of parents, influence of media and self-esteem. Height and weight were measured using a calibrated height measurement tool and a digital weighing scale. A total of 98 respondents (31.3\%) misperceived their own weight status while 215 respondents (68.7\%) accurately perceived their own weight status. Percentage of misperception (66.7\%) was higher among obese individuals compared to non-obese individuals (28.4\%). Bivariate and multivariable analyses found factors such as ethnicity, household income, mother's and father's level of education, status of obesity, eating habits, influence of media and self-esteem to be significant with misperception of own weight status. Multivariable analysis using logistic regression found mother's level of education, household income, status of obesity, eating habits and self-esteem to be significant with misperception of own weight status. Misperception of own weight status continues in the transition period from adolescents to early adulthood and can be a barrier towards leading a healthy lifestyle.
\end{abstract}

Keywords: Misperception, factors, obesity, weight status, university students.

\section{Introduction}

The perception of individuals of their own weight status and body image often incorporates visualisation of their own body formed in their mind. It is a multidimensional concept incorporating sociocultural, neurological and psychological elements ${ }^{1}$.Misperception of own weight status refers to the discordance between an individual's actual weight status and the perception of his/her weight status ${ }^{2,3}$. Studies conducted among adolescents in Hong Kong found poor agreement between the BMI and perceived weight while female adolescents were found to overestimate their weight.Meanwhile, a study conducted among Taiwanese men and women found an overestimation of body shape among women (57\%) compared to men $(12 \%)^{4}$.

A significant number of female adolescents perceived themselves as being 'too fat' although the majority had a normal range of body weight and as a result, there was an increase in eating disorders among adolescent females which increased efforts to protect adolescent girls from excessively worrying about their own weight status ${ }^{5}$. Adolescents who were classified as obese or overweight were unaware of their weight problem as very few adolescents had a perception of themselves as being too heavy ${ }^{6}$. Despite increasing attention by the media and governmental organizations of the various health problems contributed by obesity, many studies have shown that overweight adolescents and young adults were unaware of their own weight status. Therefore, misperception of weight status may affect motivation to lose weight as factors related to misperceptions of weight play a pivotal role in planning or executing efforts to reduce overweight and obesity problems ${ }^{7}$.Preference for a particular body weight and attitudes towards it may be mediated by cultural, personal and familial factors as well as an individual's own weight status. Individuals with a higher BMI were dissatisfied with their body shape and weight compared to individuals with a lower BMI while women were more dissatisfied compared to men ${ }^{8}$. Dissatisfaction of one's body image often leads to misperception of own body weight. Meanwhile, obesity in Malaysia has recently extended to rural communities, as the prevalence rate was $6.1 \%$ among rural children and serves as an early warning as to how seriously obesity prevails among children in rural communities ${ }^{9}$. Previous studies have shows and increasing trend of obesity in Malaysia from $1 \%$ in 1990 to $6 \%$ in 1997 among those aged 13 to 17 years ${ }^{10}$ and those aged 7 to 10 with an increase of $6.6 \%$ and $13.85 \%{ }^{11}$.

The prevalence of obesity among young adults aged 18 and above in Malaysia was $4.4 \%$ and continues to rise. In 2004, the overall prevalence of obesity was $12.3 \%{ }^{12}$. A higher percentage of males were found to be overweight compared to females among university students as a higher percentage of females were found to be underweight ${ }^{13}$. As adolescents and young adults are the epicenter of the of the epidemic, obesity related comorbidities often prevail into adulthood ${ }^{14}$ due to obvious shift towards high fat diets and increased sedentary behaviour $^{15}$. Obesity is associated with an individual's dissatisfaction of his or her own body weight in various 
communities among different cultures ${ }^{16}$.It was hypothesized that overweight and obese weight misperceivers would eventually lead to unhealthy weight loss attitudes and behaviors including a lack of desire to weigh less, have higher caloric intake and lower physical activity levels ${ }^{17}$.

\subsection{Study design, settings, and sampling frame}

\section{Methodology}

A cross-sectional study using questionnaires was conducted in Subang Jaya, located in the state of Selangor. Subang Jaya is well known for its tertiary education with a large number of private universities ${ }^{18,19}$. The sample was calculated based on $95 \%$ confidence interval and a $5 \%$ margin of error with the aid of the power and sample size calculation software. Therefore the sample size obtained was $272^{20}$. An additional $20 \%$ was added to the minimum sample size that was calculated using the formula to allow dropouts or rejected subjects due to the exclusion criteria. Hence the total sample size calculated was 330 subjects but only 313 participants completed the questionnaires.

\subsection{StudyInstruments}

A set of close-ended questionnaire was used as the study instrument andincluded questions on socio demographic factors, perception of weight, knowledge on nutrition and obesity, eating habits, self-esteem, influence of parents as well as influence of the media. The questionnaire was compiled using references from previous studies on the misperception of own weight status and was set in dual languages, in English and in Bahasa Malaysia to enable respondents to have a better understanding of the questions. A reliability and validity test was conducted and Cronbach's alpha $(\alpha=0.78)$ was used to assess internal consistency.

Face and content validity was conducted. A pre test was carried out among 30 university students of the same age group who were not part of the actual study and slight modifications were done after the pre test.The questionnaire was divided into 7 sections and was based on a Likert scale from 1 to 4 with a range of options such as strongly disagree, disagree, agree and strongly agree. For each of the questions answered by the respondents, a score of 1 was given to the option strongly disagree while a score of 4 was given to the option, strongly agree. Scores were inverted for negative questions and scores above the median value were categorized as correct and total scores below the median value were categorized as incorrect.

\subsection{Research Ethics}

The procedures conducted in this study were non invasive and written consents were required from all respondents who agreed to participate in this study. Approval from the Ethics Committee of the Medical Faculty of PusatPerubatan University Kebangsaan Malaysia as well as permission from the respective university was obtained prior to conducting this study.

\subsection{Statistical analyses}

The Statistical Package for Social Sciences (SPSS) version 17.0 was utilized. The results for both descriptive and analytical analysis were obtained from this study. Data were tested for normality using the Kolmogorov-Smirnov test, skewness and kurtosis, and plotting a graph. Chi square test was used for the bivariate analysis to determine the association between the variables and misperception of own weight status using significant $\mathrm{p}$ values for categorical variables. Multivariable analysis was used for the dichotomous outcome using logistic regression and the significant values obtained from the bivariate analysis. The confidence interval was $95 \%$ and the level of significance was $\mathrm{p}$ value $<0.05$.

\section{Results}

This study included 313 respondents out of which 182 (58.1\%) were female and 131 (41.9\%) were male (Table 1). The majority of respondents were of Chinese ethnicity $(49.5 \%)$ followed by those of Malay ethnicity (26.8\%), Indian ethnicity (20.2\%) and Others(3.5\%). A total of $195(62.3 \%)$ fathers received tertiary education followed by $109(34.8 \%)$ who received secondary education, and $9(2.9 \%)$ who received primary education. Meanwhile a total of $142(45.4 \%)$ mothers received tertiary education, 127(40.6\%) received secondary education, and $44(14.0 \%)$ received primary education. The median value for the level of income was RM $5000+6,305$. A total of $129(41.2 \%)$ had a total income above RM 5,000, 54 (17.3\%) respondents with a total income range of RM 4,001-5,000. Meanwhile, 33 (10.5\%) respondents had a total income range of RM 3,001-RM 4,000, 47 (15\%) with a total income range ofRM 2,001-RM 3,000, 46 (14.7\%) with and income range of RM 1,001-2,000 and 4(1.3\%) with an income of RM 1,000 and below. 
IV. Figures And Tables

Table 1 Distribution of respondents' sociodemographic characteristics $(n=313)$

\begin{tabular}{|c|c|c|}
\hline Characteristics & Frequency $(\mathrm{f})$ & Percentage (\%) \\
\hline \multicolumn{3}{|l|}{ Age (year) } \\
\hline 18 & 75 & 24.0 \\
\hline 19 & 78 & 24.9 \\
\hline 20 & 84 & 26.8 \\
\hline 21 & 76 & 24.3 \\
\hline \multicolumn{3}{|l|}{ Ethnicity } \\
\hline Malay & 84 & 26.8 \\
\hline Chinese & 155 & 49.5 \\
\hline Indian & 63 & 20.2 \\
\hline Others & 11 & 3.5 \\
\hline \multicolumn{3}{|l|}{ Sex } \\
\hline Male & 131 & 41.9 \\
\hline Female & 182 & 58.1 \\
\hline \multicolumn{3}{|l|}{ Faculty } \\
\hline Arts & 38 & 12.1 \\
\hline Business & 52 & 16.6 \\
\hline Engineering & 55 & 17.6 \\
\hline Medical & 51 & 16.3 \\
\hline Science & 48 & 15.4 \\
\hline Information Technology & 69 & 22.0 \\
\hline \multicolumn{3}{|l|}{ Level of education of mother } \\
\hline Primary education & 44 & 14.0 \\
\hline Secondary education & 127 & 40.6 \\
\hline Tertiary education & 142 & 45.4 \\
\hline \multicolumn{3}{|l|}{ Level of education of father } \\
\hline Primary education & 9 & 2.9 \\
\hline Secondary education & 109 & 34.8 \\
\hline Tertiary education & 195 & 62.3 \\
\hline \multicolumn{3}{|l|}{ Level of income of parents } \\
\hline$\leq \mathrm{RM} 1,000$ a month & 4 & 1.3 \\
\hline RM 1,001 -RM 2000 & 46 & 14.7 \\
\hline RM 2,001-RM 3000 & 47 & 15.0 \\
\hline RM 3,001-RM 4000 & 33 & 10.5 \\
\hline RM 4,001-RM 5000 & 54 & 17.3 \\
\hline$>$ RM 5,000 a month & 129 & 41.2 \\
\hline
\end{tabular}

Table 2 Association between the various factors and the perception of own weight status

\begin{tabular}{|c|c|c|c|c|c|}
\hline Factors & $\begin{array}{l}\text { Perception of own } \\
\text { weight status }\end{array}$ & Misperception & $\chi^{2}$ & $\mathrm{p}$ value & $\begin{array}{l}\text { Odds ratio } \\
(95 \%)\end{array}$ \\
\hline \multicolumn{6}{|l|}{ Age (year) } \\
\hline $18-19$ & $101(66.0)$ & $52(34.0)$ & 0.997 & 0.318 & 1.066 \\
\hline $20-21$ & $114(71.2)$ & $46(28.8)$ & & & $(0.587-1.937)$ \\
\hline \multicolumn{6}{|l|}{ Gender } \\
\hline Male & $96(73.3)$ & $35(26.7)$ & 2.209 & 0.137 & 1.793 \\
\hline Female & $119(65.4)$ & $63(34.6)$ & & & $(0.928-3.464)$ \\
\hline \multicolumn{6}{|l|}{ Ethnicity } \\
\hline Malay & $65(77.4)$ & $19(22.6)$ & 4.032 & $0.045^{*}$ & 1.661 \\
\hline Non-Malay & $150(65.5)$ & $79(34.5)$ & & & $(0.774-3.567)$ \\
\hline \multicolumn{6}{|c|}{$\begin{array}{l}\text { Household Income } \\
\text { (RM) }\end{array}$} \\
\hline High & 174(80.6) & $42(19.4)$ & 45.627 & $<0.001^{*}$ & 3.257 \\
\hline Low & $41(42.3)$ & $56(57.7)$ & & & $(1.741-6.090)$ \\
\hline \multicolumn{6}{|c|}{$\begin{array}{l}\text { Mother's level of } \\
\text { education }\end{array}$} \\
\hline High & $125(88.0)$ & $17(12.0)$ & 45.195 & $<0.001^{*}$ & 0.279 \\
\hline Low & $90(52.6)$ & $81(47.4)$ & & & $(0.136-0.574)$ \\
\hline \multicolumn{6}{|c|}{$\begin{array}{l}\text { Father's level of } \\
\text { education }\end{array}$} \\
\hline High & $149(76.4)$ & $46(23.6)$ & 14.919 & $<0.001 *$ & 1.073 \\
\hline
\end{tabular}




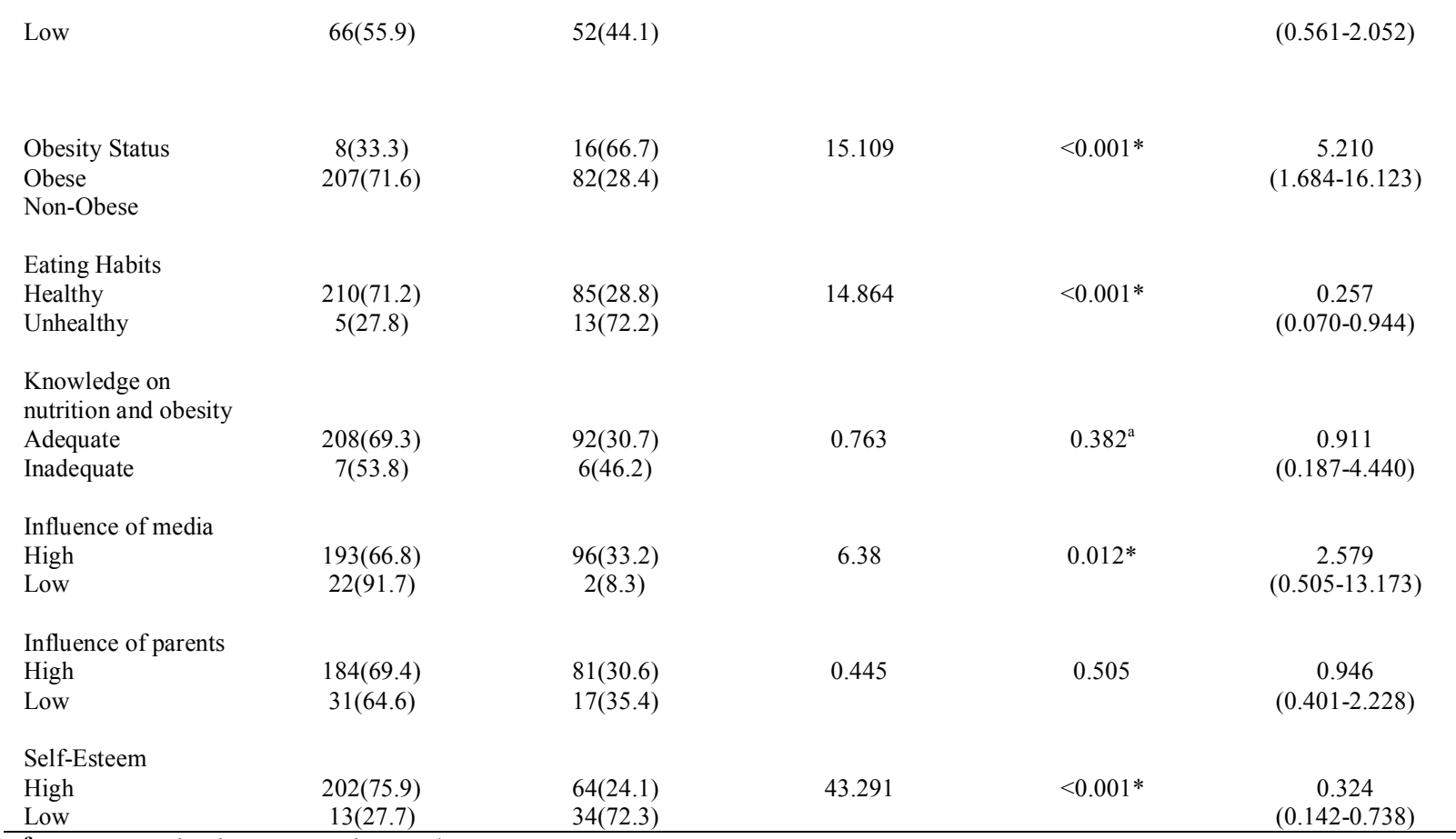

${ }^{a}$ Yates Continuity Correction , ${ }^{*} \mathrm{p}<0.05$

Table 2 shows the association between various factors and misperception of own weight status. Respondents aged 18-19 had a higher percentage of misperception of own weight status (34.0\%) compared to those aged 20-21 (28.8\%). Misperception of own weight status was higher among females (34.6\%) compared to males (26.7\%). Non-Malays had a higher percentage of misperception of own weight status (34.5\%) compared to Malays (22.6\%). Respondents with lower household income had a higher percentage of misperception (57.7\%). Meanwhile, misperception of own weight status was higher among mothers with a lower level of education $(47.4 \%)$ and the trend was similar to fathers who had a lower level of education $(44.1 \%)$. Misperception of own weight status was higher among those who were obese $(66.7 \%)$, had unhealthy eating habits (72.2.\%), with inadequate knowledge of nutrition and obesity $(46.2 \%)$, had a higher influence of media (33.2\%), had lower parental influence (35.4\%) and a lower self-esteem (72.3\%).

Table 3Logistic regression model to determine the association between various factors and misperception of

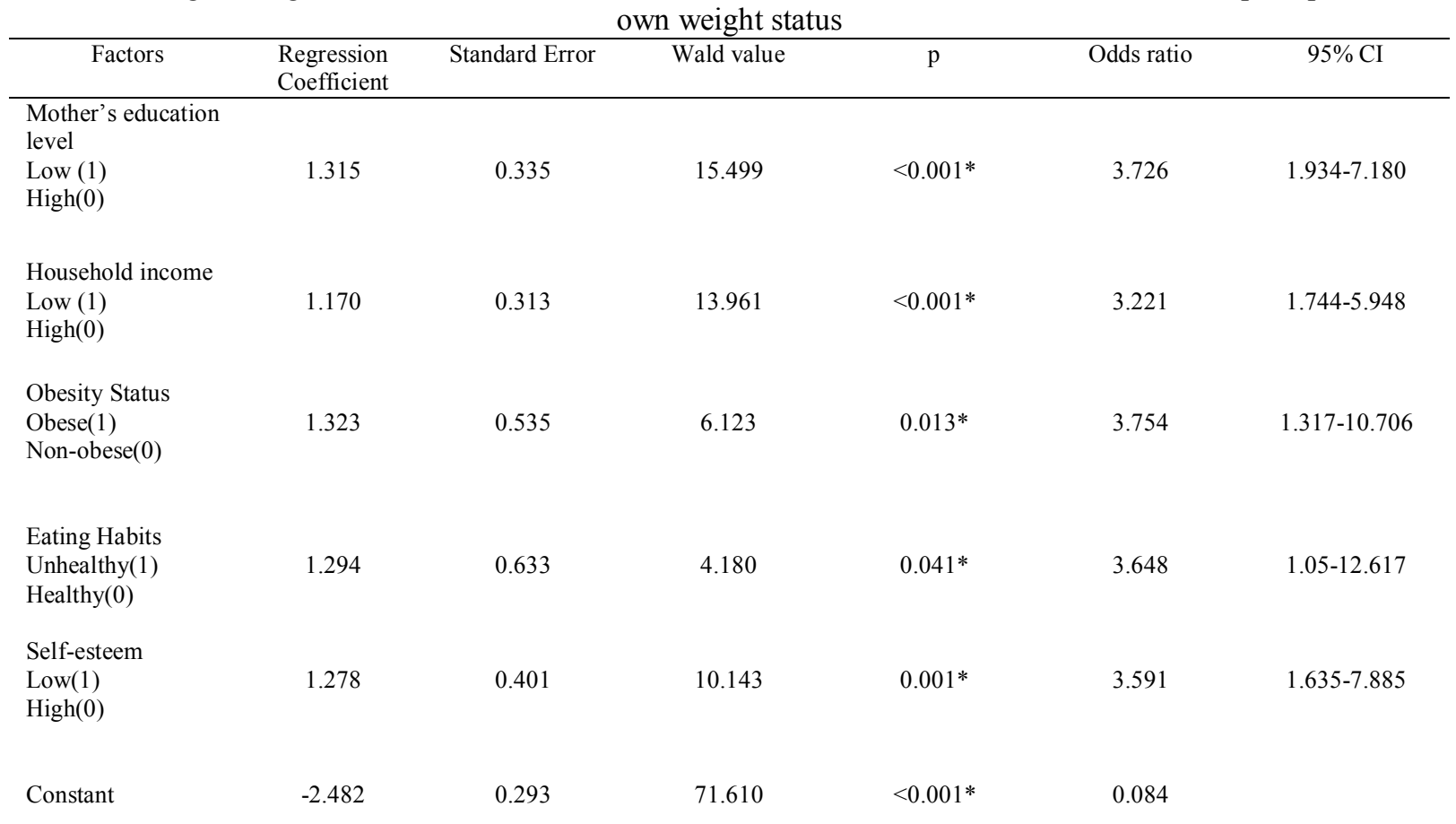


Table 3 shows the results of multivariable logistic regression. Respondents' whose mothers received a lower level of education had a greater risk (3.7 times) of misperception of own weight status while those with a lower household income also had a greater risk (3.2 times) of misperception of own weight status. Respondents who were obese had a greater risk (3.75 times) of misperception while those who had unhealthy eating habits also had a greater risk (3.6 times) of misperception. Lastly respondents with a low self-esteem had a greater risk (3.6 times) of misperception of own weight status.

\section{Discussion}

Misperception was higher among young adults aged 18-19 years old compared to those aged 20-21 years old. Previous studies showed that misperception increased from those in $9^{\text {th }}$ grade to those in $12^{\text {th }}$ grade ${ }^{21}$. Young adults aged 18-19 years old often have a warped impression of what constituted a healthy weight due the period of transition into early adulthood. The increased misperception may be influenced by social, psychological, and physical changes during the period of transition ${ }^{22}$. Females had a higher percentage of misperception of own weight status compared to males in this study. This trend was similar to a previous study that found overestimation of weight among females and underestimation of weight among males ${ }^{23}$. However, this study differed from a previous study that found a higher percentage of misperception among males compared to females ${ }^{24,25}$.

Misperception of own weight status was higher among respondents with a lower household income in this study and this was similar to a previous study that found an association between lower socioeconomic status and misperception of weight ${ }^{26}$. Lower socioeconomic status is often associated with lower level of education, which may have contributed towards an individual's skewed perception of weight. The level of education of parents often has a strong association with misperception of own weights status. This study found that respondents, whose mothers and fathers received a lower of education, had a higher percentage of misperception. This differed from a previous study that found no association between the level of education of parents and the individual's misperception of own weight status ${ }^{27}$. Another studyfoundthat individuals who obtained a high school diploma were less likely misperceive their own weight status compared to individuals who had lesser than a high school education. Education level of parents is an important element that contributes towards the cognitive development of children. Parents who have higher education level often impart good knowledge on healthy eating habits, healthy weight, and healthy physical activities. This influences the way in which adolescents and young adults perceive themselves. Parents with a lower level of education are often unable to empower their children towards healthy lifestyle and this leads to misperception ${ }^{28}$.

The total percentage of misperception in this study was $31.3 \%$ and was similar to a previous study that found the percentage of misperception of own weight status to be $29 \%$ to $33 \%$ among adolescents. This study found a higher percentage of misperception of own weight status among respondents who had unhealthy eating habits and was similar to a previous study, which associated misperception of own weight status and unhealthy dietary habits. Individuals who misperceived their weight status often went through various forms of dieting and skipped meals ${ }^{29}$. Unhealthy eating habits are prevalent among university students as university life becomes increasingly demanding and young adults tend to chose easy alternatives when it comes to food choices. Respondents with inadequate knowledge on nutrition and obesity in this study had a higher percentage of misperception of own weight status and this was similar to a previous study that found an imbalance in knowledge on nutrition and obesity that lead to problems in dietary habits and weight misperception ${ }^{30}$. This study found that respondents who had a higher influence of media had a higher percentage of misperception of own weight status. Studies found that individuals who were in their early adulthood had a more homogenized perception of weight. However, the portrayal of extremely thin women and female celebrities often affects how young adults perceive their own weight andthis affected theperception of females in choosing a lean body as ideal and therefore misperceiving their actual weight ${ }^{31}$. Absence of extremely thin males being portrayed by the media results in the preference of males for a slightly built and heavy body weight ${ }^{32}$.

Parental influence is strongly associated with misperception of own weight status. Misperception of own weight status was higher among those who had lower parental influence. This was similar to a previous study, which found that adolescents who were able to accurately assess their own weight status had a strong association with their parents' ability to accurately identify their child's weight status ${ }^{33}$. This study found that misperception of own weight status was higher among respondents with a low self-esteem as most individuals often feel less worthy of themselves ${ }^{34,35}$. The percentage of obesity in this study was $(7.7 \%)$ and obesity was higher among those aged 18 to 19 years old $(8.5 \%)$ and males $(12.2 \%)$ compared to a previous study that found obesity to be higher among females $(13.8 \%)^{7}$. Prevalence of obesity among Malays was $(8.3 \%)$ followed by Chinese (7.1\%), Indians $(9.5 \%)$ and Others $(0 \%)$ and this differed from a previous study that found obesity to be the highest among Malays (13.6\%) followed by Indians (13.5\%), 'Sarawak Bumiputra'(10.8\%), Chinese (8.5\%) 
and 'Sabah Bumiputra' $(7.3 \%)^{7}$. These various ethnic groups have different optimal body mass indexes and therefore have attitudes and body weight preferences that differ from each other ${ }^{36}$.

\section{Acknowledgement}

We would like to thank the Ethical Committee of UniversitiKebangsaan Malaysia for their funding and approval of this project and the university students involved in this study.

\section{Conclusion}

Misperception of own weight status was found to be (31.3\%) and the factors that were significantly associated were ethnicity, household income, mother's and father's level of education, status of obesity, eating habits, influence of media, influence of parents and self-esteem. A larger sample size covering a wider population of young adults could improve the outcome of this study.Health education targeted towards young adults and the coordination of health education related programmes in universities are important. Nutritional standards need to be set for food and beverages sold at universities. The promotion of high quality physical education would enable young adults to adopt a healthy and active lifestyle.

\section{References}

[1]. H John, The Causal Theory of Perception, The Philosophical Quarterly,42(168), 1992, 277-296.

[2]. T.F.M. TerBogt, S.A.F.M. Van Dorsselaer, K. Monshouwer, J.E.E. Verdurmen, R.C.M.E. Engels, and \& W.A.M. Vollebergh, Body Mass Index and Body Weight Perception as Risk Factors for Internalizing and Externalizing Problem Behavior Among Adolescents, Journal of Adolescent Health, 39, 2006, 27-34.

[3]. M.M. Combs, Body Perception among College Students and the Relation to Personal Characteristics and Health Lifestyle Behaviors, School of Allied Medical Professions, 2009.

[4]. M.M.C.Wong, S. Tso, and S.S.Y.Lui, Accuracy of Body Weight Perception and Figure Satisfaction in Young Adults with Psychotic Disorders in Hong Kong,Hong Kong Journal of Psychiatry, 19,2009,107-111.

[5]. R. Standley, V. Sullivan, and J. Wardle. J, Self-perceived weight in adolescents: Over-estimation or under-estimation? Journal of Body Image, 6, 2006, 56-59.

[6]. T. D. Cook, M.R. Herman,M. Phillips, and R.A. Settersten, Some ways in which neighborhoods, nuclear families, friendship groups, and schools jointly affect changes in early adolescent development,Journal of Child Development,73, $2002,1283-1309$.

[7]. E.C. Miller, M.R Schulz, D.L. Bibeau, A.M. Galka, L.I. Spann, L.B. Martin, R.E. Aronson, and \& C.M Chase, Factors Associated with Misperception of Weight in the Stroke Belt, Journal of General Internal Medicine, 2008, 323-327.

[8]. Z.Y.Tan, and H.S.Yim, Weight Status, Body Image Perception and Physical Activity Malay Housewives in KampungChengkauUlu, Negeri Sembilan, International Journal for the Advancement of Science \& Arts, 1(1),2010, 35-43.

[9]. A.S.L.Bong, and J. Safurah, Obesity Among Year 1 and 6 Primary School Children in Selangor DarulEhsan,MalaysianJournal of Nutrition, 2, 1996, 21-27.

[10]. M.N.Ismail, andE.N. Vickneswary, Prevalence of Obesity in Malaysia: Data from Three Ethnic Groups, Country Report at the Asian BMI/Obesity Workshop,1999.

[11]. M.N. Ismail, andC.L. Tan, Prevalence of Obesity in Malaysia,Country Report at the Regional Advisory Meeting on Obesity. Manila Philippines, 1998.

[12]. G.R.L.Rampal,M.S. Sherina, S. Rampal, D.W.Y. Jie, P.L. Chow, J.S. Liew, and Y.S. Shu, Prevalence of Overweight Among Secondary School Students in Klang District, Selangor, Malaysian Journal of Nutrition,13(1),2007,1-8.

[13]. G.L. Khor, L. Cobiac, andG. Skrzypiec, Gender Differences in Eating Behaviour and Social Self Concept among Malaysian University Students, Malaysian Journal of Nutrition,8(1),2002, 75-98.

[14]. S.G. Hassink, Pediatric Obesity: Prevention, Intervention and Treatment Strategies for Primary Care(United States of America:American Academy of Pediatrics, 2007).

[15]. N. Cameron, N.G. Norgan, and G.T.H. Ellison,Childhood Obesity: Contemporary Issues. Childhood Obesity (Taylor and Francis, 2006).

[16]. M.J. Pallan, L.C. Hiam, J.L. Duda, and P. Adab, Body Image, Body Dissatisfaction and Weight Status in South Asian Children: A cross-Sectional Study, BiomedcentralPublic Health Journal, 11 (21),2011, 1-8.

[17]. D.T. Duncan, K.Y. Wolin, M. Scharoun-Lee, E.L. Ding, E.T. Warner, and G.G. Bennett, Does perception equal reality? Weight misperception in relation to weight-related attitudes and behaviors among overweight and obese US adults, International Journal of Behavioral Nutrition and Physical Activity, 8(20),2011, 2-9.

[18]. Best Practices Database. Subang Jaya Municipal Council Community Recycling Centre.2009.http://www.ucl.ac.uk/dpuprojects/drivers urb change/urb infrastructure/pdf publ ic_private_services/BestPractice_Subang_Jaya_Recycling_Centre_Malaysia.pdf(accessed 24 November 2012).

[19]. SubangJaya.Selangor, 2012; Available fromhttp://www.touristlink.com/malaysia/subang- jaya/overview.html (accessed 24 November 2012).

[20]. J.L. Fleiss,Statistical Methods for Rates and Proportions (New York: John Wiley Sons, 1981)

[21]. K.S. Talamayan, A.E. Springer, S.H. Kelder, E.C. Gorospe, and K.A Joye, Prevalence of Overweight Misperception and Weight Control Behaviours Among Normal Weight Adolescents in The United States. The Scientific World Journal,6, 2006, $365-373$

[22]. L.W. Pon, M. Kandiah, and N.M.T. Mohd, Body Image Perception, Dietary Practices and Physical Activity of Overweight and Normal Weight Malaysian Female Adolescents,Malaysian Journal of Nutrition, 10(2), 2004,131-147.

[23]. P.X. Kuan, H.L. Ho, M.S. Shuhaili, A.A. Siti and H.R. Gudum, Gender Differences in Body Mass Index, Body Weight Perception and Weight Loss Strategies among Undergraduates in Universiti Malaya Sarawak, Malaysian Journal of Nutrition, 17(1), 2011, 6775.

[24]. G.G.Bennett, and K.Y.Wolin, Satisfied or Unaware? Racial differences in perceived weight status, International Journal of Behavioral Nutrition and Physical Activity,3(40), 2006, 1-5.

[25]. N.M.Edwards, S. Pettingell, I.W. Borowsky, Where perception meets reality: Self- perception of weight in overweight adolescents, Journal of the American Academy of Pediatrics, 125 (3), 2010,452-459.

[26]. M.A.Burke, F.Heiland, and C.M. Nadler, Fromoverweight' to 'about right': Evidence ofa generational shift in body weight norms, Journal of obesity, 18,2010, 1226-1234. 
[27]. S. Bhanji,A.K. Khuwajal, F. Siddiquil, I. Azam, and K. Kazmi, Underestimation of weight and its associated factors among overweight and obese adults in Pakistan: a cross sectional study,BiomedcentralPublic Health Journal, 11(363), 2011,2-8.

[28]. G. Kopelman, I.D. Caterson, and W.H. Dietz, Clinical Obesity in Adults and Children, ( Oxford, U.K: Blackwell Publishing, 2010).

[29]. R.S.Strauss, Self-reported weight status and dieting in a cross-sectional sample of young adolescents,Archives of Pediatric and Adolescent Medicine, 153,1999, 741-747.

[30]. N.A. Muhammad, K. Omar, S. Azhar Shah, L. Muthupalaniappen, and F. Arshad, Parental perception of their children's weight status and its association with their nutrition and obesity knowledge, Asia Pacific Journal of Clinical Nutrition, 17(4), 2008, $597-$ 602.

[31]. R.T. Mikolajczyk, A.E. Maxwell, W.E. Ansari, C. Stock, J. Petkeviciene, and F.G. Grima, Relationship between perceived body weight and body mass index based on self- reported height and weight among university students: a cross-sectional study in seven European countries, Journal of Biomedcentral Public Health, 40(10), 2010, 1-11.

[32]. J. Wardle, A.M. Haase, and A. Steptoe, Body image and weight control in young adults, International comparisons in university students from 22 countries, International Journal of Obesity, 30,2006, 644-651.

[33]. J.S. Huang, M. Donohue, K. Becerra,andR. Xu, Relationship between parents' and children's weight perceptions,Journal of Infant, Child and Adolescent Nutrition, 1(1),2009, 15-20.

[34]. A. Furnham,N. Badmin, I. Sneade, Body image dissatisfaction: Gender differences in eating attitudes, self-esteem and reasons for exercise, The Journal of Psychology, 136(6),2002, 581- 596.

[35]. E.M. Perrin, J. Boone-Heinonen, A.E. Field, T. Coyne-Beasley, and P. Gordon-Larsen. Perception of 95 overweight and selfesteem during adolescence. International Journal of Eating Disorder, 43(5), 2010, 447-454.

[36]. D. Mellor, M. McCabe, L. Ricciardelli, J.Yeow, N. Daliza, \&N.F.M. Hapidzal,Sociocultural influences on body dissatisfaction and body change behaviors among Malaysian adolescents,Journal of Body Image,6, 2009, 121-128 